\title{
Monkey auditory list memory: Tests with mixed and blocked retention delays
}

\author{
ANTHONY A. WRIGHT \\ University of Texas Medical School, Houston, Texas
}

\begin{abstract}
A rhesus monkey was tested in an auditory list memory task with blocked and mixed retention delays. Each list of four natural or environmental sounds (from a center speaker) was followed by a retention delay $(0,1,2,10,20$, or $30 \mathrm{sec})$ and then by a recognition test (from two side speakers). The monkey had been tested for 12 years in tasks with blocked delays. An earlier ( 4 years prior) blocked-delay test was repeated, with virtually identical results. The results from the mixed-delay test were likewise similar. Thus, the peculiarities of blocked-delay testing, such as delay predictability or differences in list spacing, apparently do not alter this monkey's memory for auditory lists. It is concluded from this and other evidence that the monkey's serial position functions reflectmnemonic processes that change with changes in retention delay and are not artifacts of the blocked-delay procedure. The nature of the monkey's auditory memory is discussed.
\end{abstract}

List memory tasks allow the study of memory processes in a way that is not possible with single-item memory tasks. For example, the recency effect, good memory for items last on a list, was shown some time ago to be selectively eliminated by delaying recall and filling the delay with distractor activity (e.g., Glanzer \& Cunitz, 1966; Postman \& Phillips, 1965). This result was interpreted as evidence that the recency effect represents a short-term memory (STM) store that decays with time. Another memory process that can be studied with list memory tasks is the primacy effect. The primacy effect is good memory for items first in a list and was thought to represent a long-term memory (LTM) store, because it was correlated with variables (e.g., rehearsal) thought to be crucial to LTM (e.g., Rundus, 1971). These primacy and recency effects are undoubtedly signatures of memory processes, but other evidence makes it unlikely that they represent LTM and STM, and what they represent is in considerable doubt (e.g., Baddeley \& Hitch, 1977; Bjork \& Whitten, 1974; Crowder, 1993; Glenberg, Bradley, Kraus, \& Renzaglia, 1983; Roediger \& Crowder, 1976; Wright et al., 1990).

Tests of (nonhuman) animal memory may be particularly well suited to address some of these issues, because explanations based on language (e.g., the phonological loop) do not apply. Animals have been studied in list memory tasks only recently, because of the extreme difficulty in training animals in list memory tasks. Many of these difficulties have been overcome, and different

This research was supported by PHS Grants DA-10715 and MH54167. The author gratefully acknowledges the careful assistance of Jackie Rivera. Correspondence concerning this article should be addressed to A. A. Wright, University of Texas Medical School at Houston, Department of Neurobiology and Anatomy, P.O. Box 20708, Houston, TX 77225 (e-mail: anthony.a.wright@uth.tmc.edu). species, including apes, monkeys, pigeons, and rats, have been trained in list memory tasks (Bolhuis \& van Kampen, 1988; Buchanan, Gill, \& Braggio, 1981; Castro, 1995, 1997; Castro \& Larsen, 1992; Harper, McLean, \& Dalrymple-Alford, 1993; Kesner \& Novak, 1982; Reed, Croft, \& Yeomans, 1996; Roberts \& Kraemer, 1981; Sands \& Wright 1980a, 1980b; Santiago \& Wright, 1984; Wright, 1999b; Wright, Santiago, \& Sands, 1984; Wright, Santiago, Sands, Kendrick, \& Cook, 1985). In most of these cases, the serial position functions (SPFs) resemble those from humans. Furthermore, some of these different species (rhesus monkeys, capuchin monkeys, and pigeons) have shown orderly changes in their visual SPFs with changes in retention delay that resemble those for humans (Knoedler, Hellwig, \& Neath, 1999; Korsnes, 1995; Korsnes \& Magnussen, 1996; Korsnes, Magnussen, \& Reinvang, 1996; Neath, 1993; Neath \& Knoedler, 1994; Wright et al., 1985).

Training animals in these list memory tasks is time consuming. It would probably be fair to say that such training approaches the limits of our techniques, patience, and even the cognitive capacities of the animals being tested. Notwithstanding these training difficulties, extending training to lengthy retention delays has been an even greater challenge. We have found that it required the better part of a year, sometimes two, to adequately train monkeys at the longest delays used (20 and $30 \mathrm{sec}$ ) in our visual and auditory list memory tasks. Performance at these long delays gradually improved from only slightly better than chance performance to a stable accuracy level in the range of about $75 \%$ correct. Typically, we began training list memory performance at a 0 -sec delay. Under this condition, the list was presented, and the test followed immediately. Retention delays of 1 and $2 \mathrm{sec}$ were then introduced in blocks of trials and were alternated with blocks of 0 -sec delay training. Then, de- 
lays of 10, 20, and $30 \mathrm{sec}$ were successively introduced in the same manner. If performance deteriorated in the 0 -sec delay condition, the longest delays were progressively removed until accurate performance returned again to the 0 -sec baseline condition. This gradual introduction and titration of the testing delay is important because, otherwise, performance at all delays will probably deteriorate. In such instances, the monkey basically gave up performing the task. Training then had to begin all over again with shorter lists and, sometimes, even with pairs of items. Notwithstanding these possible pitfalls, we found that with this training regime, performance did become accurate at delays of $30 \mathrm{sec}$, or even more. With respect to the purpose of this article, performance was better maintained if the different delays were introduced and tested in blocks of trials, rather than the delays being randomly intermixed. For these reasons, all of our tests of the monkey's visual and auditory memory were conducted with different retention delays tested in blocks of trials.

Testing retention delays in blocks of trials does, however, have potential drawbacks. One potential problem is that the time between list presentations will vary as a function of retention interval delay. For example, in the 30 -sec delay condition, each list in the block will be separated by $30 \mathrm{sec}$ more than in the 0 -sec delay condition. List separation could, in principle, affect the shape of the different delay functions by diminishing proactive interference (PI) across lists. If so, the effect of list separation and delay would be confounded (Michael J. Watkins, personal communication, manuscript review, October 1998). Another potential problem is that if delays are tested in blocks of trials, the monkey could conceivably change its behavior (e.g., its performance strategy) as a function of delay. If so, the effects of a change in memory strategy and of delay would be confounded (George Sperling, personal communication, December 1997). Although such strategic changes by monkeys might be unlikely, there is really no way to tell for sure without testing for it. The catch, however, is that good memory performance would have to be maintained during the test, or else the test would be meaningless. Nevertheless, a monkey trained in the task for a long time might eventually get over being disrupted by mixed delays. To determine whether this would be the case was the purpose of the experiment reported in this article.

For this purpose, in the experiment reported in this article, a monkey was tested that had been trained in the auditory list memory task with blocked retention delays for 12 years before the experiments reported here were begun. A blocked-delay test with the same conditions and procedures as the present experiment had been conducted 4 years earlier. In order to provide a valid comparison with the mixed-delay test and because the degree and nature of disruption by the mixed-delay test was unknown, the blocked-delay test was first repeated, so that I could evaluate the stability of the SPFs before the mixed-delay test was conducted. If the mixed-versus blocked-delay results turned out to be similar, these results would substantiate the hypothesis that the blockeddelay SPFs and their changes with changes in retention delay were due to the same memory processes as with mixed delays.

\section{METHOD}

\section{Subject}

The subject in this study, B.W., was a 20-year-old male rhesus monkey (Macaca mulatta). He was maintained in state and federal approved facilities and was fed and watered approximately $2 \mathrm{~h}$ after experimental sessions, which were conducted 5 or 6 days per week. On nonexperimental days, food (monkey chow) and water were, for the most part, unrestricted, and his diet was supplemented with fresh fruits and vegetables. He had extensive training in the auditory list memory task prior to beginning the experiment repeated in this article (Wright, 1998b; Wright \& Rivera, 1997). Extensive training was essential because this is a very difficult task for monkeys to learn and perform reliably. Another monkey, F.D., had participated along with B.W. in previous auditory list memory experiments but unfortunately had died before this experiment could be conducted.

\section{Apparatus}

The test chamber was a modified primate cage, $58.4 \mathrm{~cm}$ wide, $58.4 \mathrm{~cm}$ deep, and $77.5 \mathrm{~cm}$ high (inside dimensions). It was located in a room with sound-deadening material on the walls. Three cage bars were removed to allow easy access $(6.7 \times 20.3 \mathrm{~cm})$ for the monkey to touch copper screens $(10.2-\mathrm{cm}$ diameter) in front of speakers. Touching the sound sources proved critical to learning the task (see Harrison, Iversen, \& Pratt, 1977).

Three speakers were located outside of the cage, as is shown in the schematic in Figure 1. The center speaker was centered on the cage wall opposite the door and was $47 \mathrm{~cm}$ from the cage floor. The side speakers were located $35.6 \mathrm{~cm}$ from the center-speaker wall and $47 \mathrm{~cm}$ from the cage floor. Tubes for dispensing Tang orange drink were located on each sidewall. The tube on the right wall was $5.1 \mathrm{~cm}$ below and $5.1 \mathrm{~cm}$ to the right of the center of the rightspeaker touch screen. The one on the left wall was $5.1 \mathrm{~cm}$ below and $5.1 \mathrm{~cm}$ to the left of the center of the left-speaker touch screen. Touches were electrically monitored with high-impedance interfaces to a computer. A computer controlled the experiment and was used to collect and analyze data.

\section{Procedure}

A trial began with a sequential presentation of four list sounds from the center speaker. Each sound was presented for $2 \mathrm{sec}$, with a 1 -sec interval between sounds. After presentation of the list sounds, there was a retention interval $(0,1,2,10,20$, or $30 \mathrm{sec})$, and then a test sound was presented simultaneously from both side speakers. It is important to emphasize that the same sound was always presented simultaneously from both side speakers; different sounds were never presented.

In these tests, 72 different sounds were presented daily. Sounds heard on any trial would not be heard again for several days. The sounds were randomly selected (without replacement) from a pool of 520 sounds. The sequences of same and different trials varied daily. The natural/environmental sounds were computer-digitized and computer-controlled selections from 13 records (Elektra Records, New York) used by radio disc jockeys for sound effects (e.g., bongo drums, water gurgling, reveille, insect buzzing, cash register bell, horse race announcer, propeller plane engine starting, toy train whistle, girls giggling, coins dropping, ducks quacking, xylophone, eggs cracking, referee whistle, dice shaking in cup, yodeling, geese, 

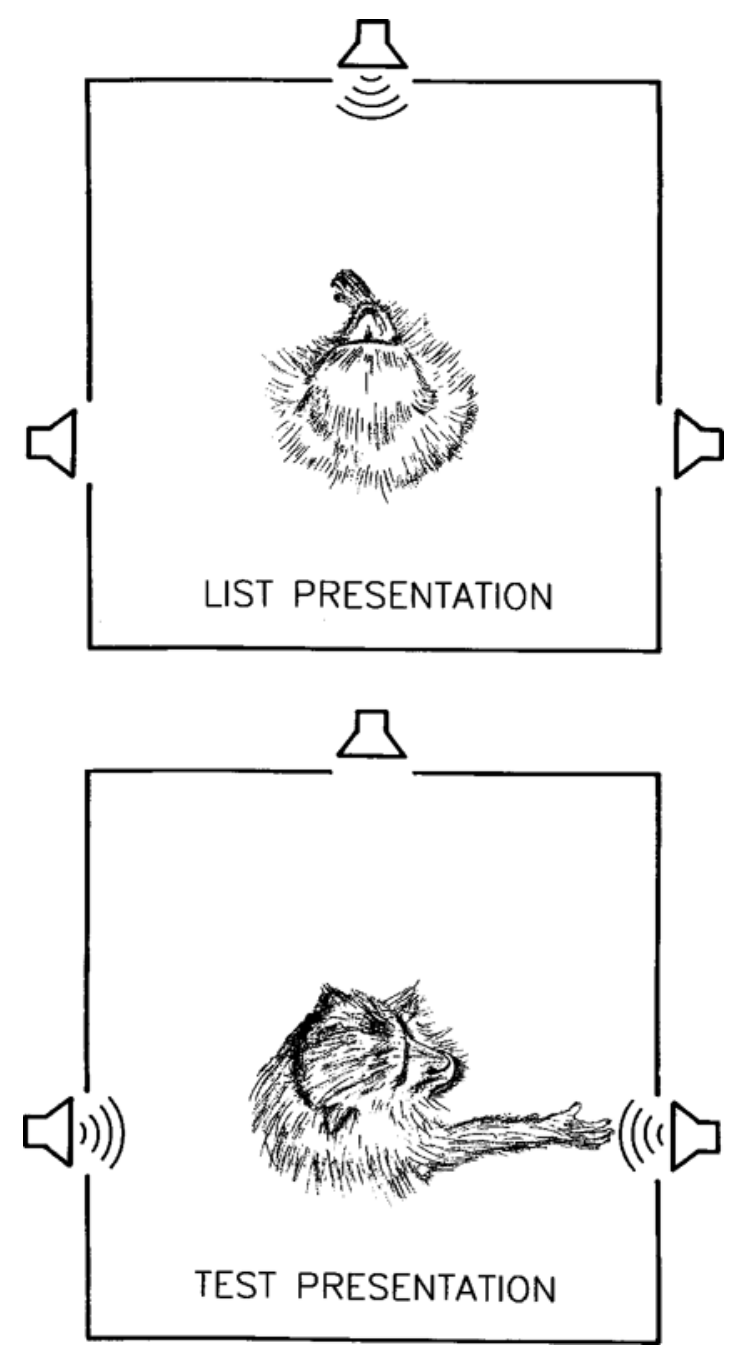

Figure 1. Auditory testing schematic. The upper panel is the top view of the monkey, with list sounds presented from a center speaker. The lower panel is the top view of the monkey touching a right-side speaker, with a test sound presented from both side speakers following list presentation. A touch to the right-side speaker was correct when the test sound matched one of the list sounds; otherwise, a left touch was correct.

lion roar, electric drill, children's piano, motorcycle, squeaky door, sneezing, crumpling paper, frogs, etc.; for other examples of sounds, see Wright, 1998a, 1998b, 1999a; Wright \& Rivera, 1997).

A single test sound followed each list and was presented for 2-6 sec. A choice response was accepted after $2 \mathrm{sec}$, and the choice response terminated the test sound. If the test sound matched one of the list sounds (same), a touch to the right-side speaker produced $3.5 \mathrm{ml}$ of Tang orange drink from the right juice spout. If the test sound matched none of the list sounds (different), a touch to the left side speaker produced an orange drink reward from the left juice spout. Failure to make a choice during the $2-6$ sec response period or an incorrect choice resulted in a 30 -sec time out and no reward.

An intertrial interval (ITI) followed a reward or a time out. The ITI varied quasi-randomly from 12 to $27 \mathrm{sec}$ in 1 -sec steps, so that there would not be any time cue for the beginning of a trial. Thus, any serial position primacy effect could not be attributed to the monkey's anticipating the beginning of a trial on the basis of a time cue. Presentation of the 16 different ITI values was counterbalanced over blocks of four sessions. Sixteen trials were conducted daily. Occasionally, B.W. would not complete sessions (possibly owing to his advanced age), and the remainder of any uncompleted session was completed on the following test day.

For the blocked test, a particular retention delay $(0,1,2,10,20$, or $30 \mathrm{sec}$ ) was tested on all 16 trials in each daily session. Each serial position was tested twice daily. The order of delay testing varied according to a Latin-square design every 6 days of testing. In order to evaluate and ensure stable results from the blocked test, each retention interval was tested 20 times, for a total of 120 daily test sessions.

For the mixed test, the retention interval delays $(0,1,2,10,20$, and $30 \mathrm{sec}$ ) were quasi-randomly selected and tested during 16 trials of daily sessions. Tests at each serial position and at each retention interval were counterbalance d over successive 3-session blocks. There was a total of 36 daily test sessions. For each delay, each serial position was tested 12 times. An analysis of the previous blocked experiment had shown that this number of tests would be adequate to define the SPFs.

\section{RESULTS}

The results from both the blocked tests and the mixed test are shown in Figure 2. The top panel shows the results for this monkey from an earlier blocked-delay test (Wright, 1998b). The middle panel shows the results for this monkey retested 4 years later in the same blockeddelay test. The results from these two tests were very similar with regard to level of performance, shapes of the SPFs, and changes in the shapes of the functions with retention interval. A three-way analysis of variance (ANOVA) was conducted, with overall performance at each serial position divided into four successive blocks (for the replication measure). There was no effect of delay, reflecting a similar overall performance level across delays $[F(5,144)=0.9, p>.6]$. There was no test $X$ delay interaction, reflecting similar levels of performance at the different delays in the two tests $[F(5,144)=$ $0.3, p>.8]$. There was, of course, a highly significant serial position $\times$ delay interaction, reflecting differences in the slopes of the SPFs for different delays $[F(15,144)=$ $18.2, p<.0001]$. For the purposes of this comparison, an important result was a nonsignificant test $X$ delay $\times$ serial position interaction, reflecting similar slopes of the functions at the different delays in the two tests $[F(15,144)=0.5, p>.9]$.

The primacy effect at the shortest delay $(0 \mathrm{sec})$ showed a very high level of accuracy of $95 \%$ correct or better. Performance at the end of the list was below chance, $45 \%$ correct or less. Similar results were shown for the $1-\mathrm{sec}$ retention interval delay. At $2 \mathrm{sec}$, the SPF changed markedly. At this retention delay, a prominent recency effect emerged. Along with this emergence of the recency effect, the primacy effect fell to $70 \%$ correct. For further increases in delay, the recency effect further strengthened to better than $80 \%$ correct, and the primacy effect further fells into the $40 \%-45 \%$ correct range. Thus, the SPFs and their changes with changes in reten- 

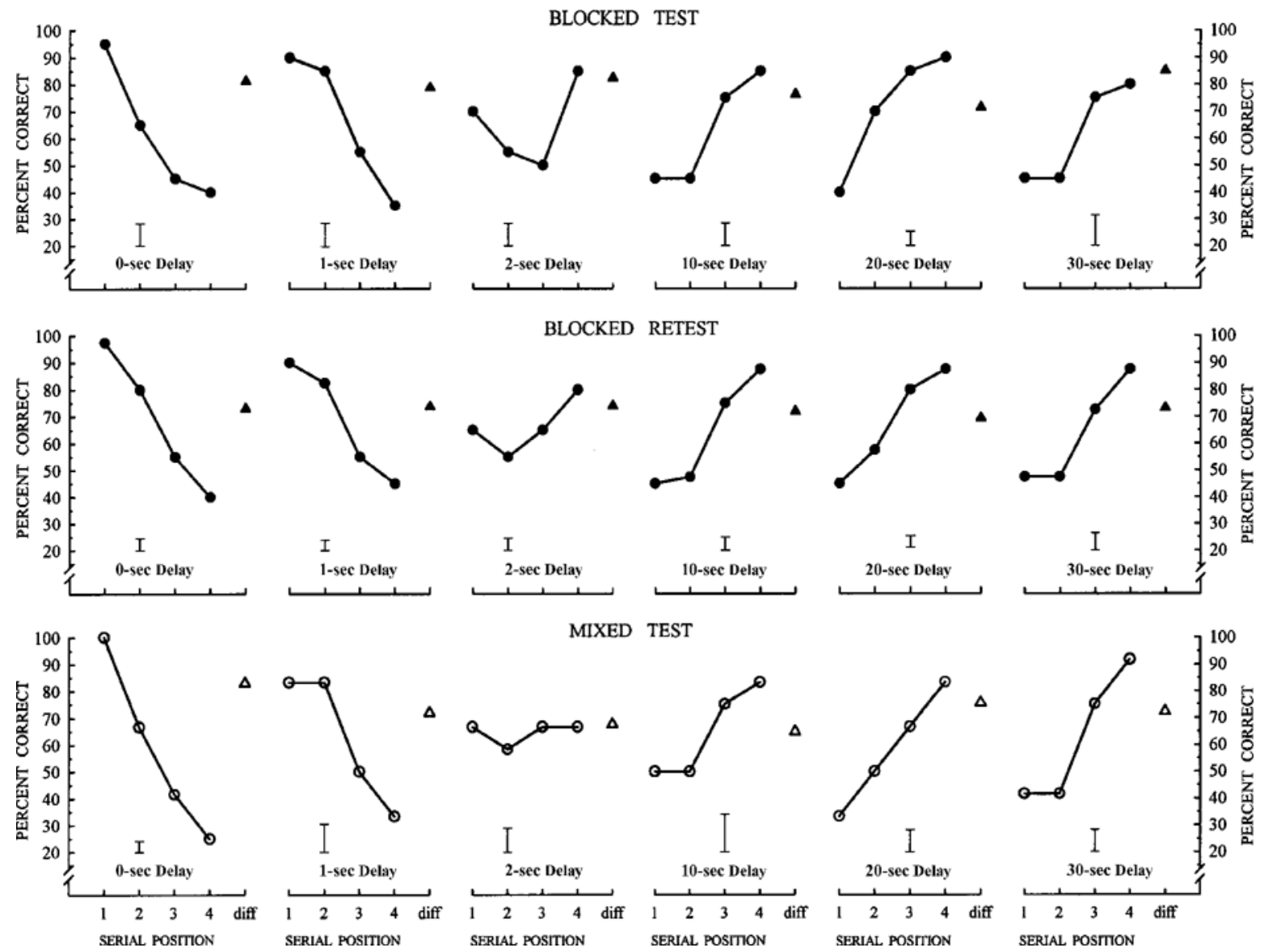

Figure 2. Auditory serial position functions for B.W. The circles show performance on trials in which the test sound matched one of the four list sounds; Serial Position 1 is the first list item. The triangles show performance on trials (diff) in which the test sound matched no list sound. The top panel is a test in which retention delays were presented in blocks of trials (Wright, 1998). The middle panel is a retest of the blocked delays 4 years later. The bottom panel is a test in which retention delays were mixed. Error bars are the mean standard errors for the four serial positions of each function. "Delay" is the retention delay in seconds.

tion interval had remained very stable over the 4 years between the two tests.

The results from the mixed retention delay test are shown in the bottom panel of Figure 2. The SPFs from this test were very similar to those from the blocked tests in terms of performance levels and changes in the SPFs with changes in the retention interval. In order to more precisely compare the results from these two tests, the results from the mixed test and the blocked retest of the present experiment are superimposed in Figure 3. Figure 3 shows that the results from these two tests were highly similar in level and shape. One could point to minor dif-
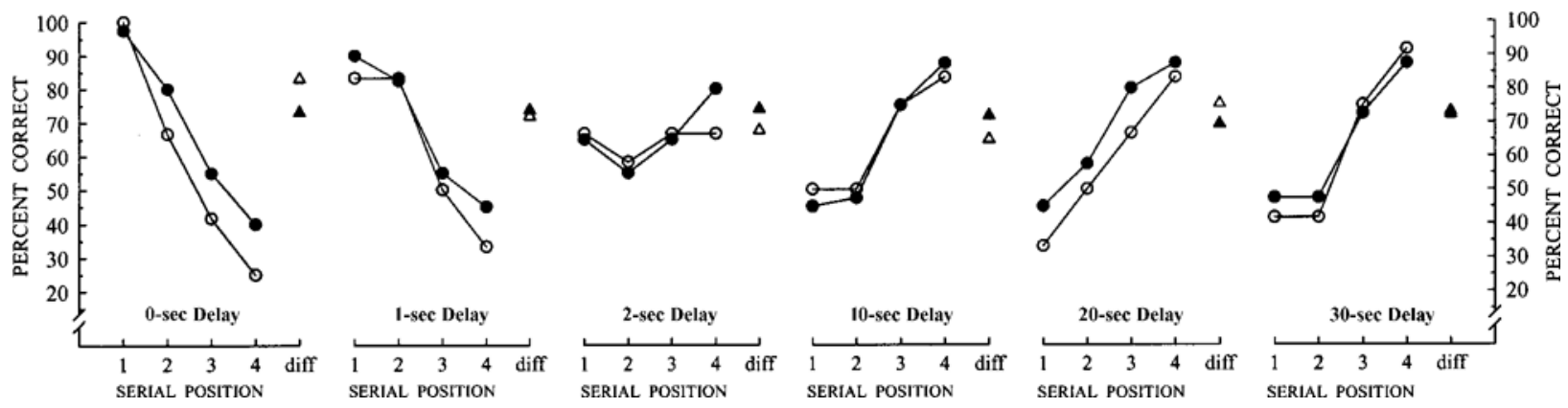

Figure 3. Superimposition of the mixed-delay test results (bottom panel of Figure 2) on the blocked-delay retest results (middle panel of Figure 2). 
ferences, such as the slightly steeper slope for the mixeddelay 0 -sec function, but it could be argued that this was just a further accentuation of the already robust performance drop (55\%) seen in the blocked retest.

The mean error bars for the mixed-delay test (see Figure 2) are somewhat greater than those for the blockeddelay tests, because of fewer tests. These and other measures of replication and variability for this single subject came from dividing performances into four successive blocks. Other ways of dividing performances did not substantially alter any of the conclusions. A three-way ANOVA on the results of the mixed test and the blocked retest showed no effect of delay, reflecting a similar overall performance level across delays $[F(5,144)=0.1, p>$ .9]. There was no test $\times$ delay interaction, reflecting similar levels of performance at the different delays in the two tests $[F(5,144)=0.5, p>.8]$. There was, of course, a highly significant serial position $\times$ delay interaction, reflecting differences in the slopes of the SPFs for different delays $[F(15,144)=15.3, p<.0001]$. As in the previous statistical test, perhaps the most important result was a nonsignificant test $\times$ delay $\times$ serial position interaction, reflecting similar slopes of the functions at the different delays in the two tests $[F(15,144)=0.3, p>$.9] .

The rhesus monkey's auditory SPFs from each of the three tests show that the recency effect gradually grew as retention delay increased and that the primacy effect dissipated. This is exactly the opposite of what happens with visual memory. In tests of the rhesus monkey's visual memory, it is the recency effect that dissipates and the primacy effect that grows with retention delay (e.g., Wright et al., 1984). These modality differences, what they might mean, how they compare with those for other species, and how they might be explained are topics in the Discussion section, following a summary of the experimental findings.

\section{DISCUSSION}

The experiments in this article showed that auditory SPFs were virtually identical over a 4 -year period between the two blocked-delay tests. The absolute performance levels, as well as the changes of the primacy and recency effects with changes in retention delay, were virtually identical. I think that these results show remarkable stability, particularly considering the difficulty of the task and the long time between tests. Accurate memory performance, particularly at the longest delays of 20 and $30 \mathrm{sec}$, gradually improved over several months in the early stages of training. Even after performance became accurate at all retention delays, randomly mixing the delays typically disrupted performance, and this disruption could linger well after a return to blocked-delay testing. Nevertheless, after this monkey became very familiar with the task, mixing the retention delays no longer disrupted performance. The mixed-delay results were virtually identical to the blocked-delay results. Both conditions produced virtually the same SPFs across retention delays. This similarity of mixed- and blockeddelay results rules out the possible explanation that changes in the SPFs might result from different strategies for different delays, because of the predictability of the memory delay in the blocked condition. It also rules out explanations based on the possibility that the additional time between lists with long delays in the blocked condition might have changed the shape of the SPFs as the delay increased. By ruling out these possibilities and explanations, the focus of this research can concentrate on the true mnemonic processes responsible for these dynamically changing SPFs.

In contrast to the pattern of changes shown for auditory SPFs, visual SPFs have shown an opposite pattern of changes for both animals (pigeons, capuchin monkeys, and rhesus monkeys) and humans (e.g., Korsnes, 1995; Neath, 1993; Wright, 1999b; Wright et al., 1985). Visual SPFs have shown pure recency changing to pure primacy, whereas auditory SPFs have shown pure primacy changing to pure recency. The auditory findings, particularly poor recognition, initially, of the last auditory item, are somewhat odd and counterintuitive, but they have been replicated in 12 independent experiments, including the present experiment (see Wright, 1998b, 1999a; Wright \& Roediger, 2002).

Human auditory SPFs have not shown the same pattern of changes as the monkey auditory SPFs, but it is difficult to make direct comparisons, owing to procedural differences. There is a so-called modality effect (superior auditory vs. visual recency; see, e.g., Greene, 1992), but typically, much longer lists have been used, and retention delays have not been manipulated. Knoedler et al. (1999, Experiment 3) used short "auditory" lists and manipulated delay and found a pattern of SPF changes that resembled visual SPFs. The problem with this study lies in whether it represents auditory memory apart from visual memory. The "auditory" items were visually presented (written) words on a computer screen that were read aloud and were names of objects that could easily be visualized. Another short-list auditory experiment used lists of five different notes (Surprenant, 2001). Lists were presented in pairs. On half the trials, one note from the second list was changed from the first list and participants judged whether the two lists were same or different. It is unclear what effect testing with a second list or using notes that might configure into a tune might have on the SPFs. Nevertheless, it is telling that recency weakened and primacy strengthened for 2-sec delay SPFs, as opposed to 0 -sec delay SPFs. One possible outcome is that monkey and human auditory memory would be shown to be fundamentally different. However, I have found (unpublished pilot experiments) that it is much more difficult to test "pure" human auditory memory than to test "pure" visual memory (e.g., with kaleidoscope patterns). Unlike visual items, auditory items "unfold" in time, and subjects often fragment the stimulus and code distinctive features. Distinctive feature coding can take the form of "visual" coding even with auditory stim- 
uli (see, e.g., Campbell \& Dodd, 1980). If visual coding were to occur, it would be no surprise that "auditory" SPFs would look like visual SPFs.

As to why the monkey's auditory memory system might be different from its visual memory system, a possible clue may be found from tests of associative learning that show that visual stimuli are more easily associated with food and auditory stimuli with danger, rather than the other way around (e.g., Shapiro, Jacobs, \& LoLordo, 1980). From this evidence, the following account was derived. For visual memory, if an animal has had good luck foraging for food in one patch (e.g., under a pine tree), it will need to remember (visual recency, short delay) to go to a similar patch (e.g., another pine tree) to continue feeding. If, on the other hand, an animal has fed in a diurnally depleting patch (e.g., berries that ripen in the morning), it will need to remember (visual primacy, long delay) to go to this same patch first thing the next morning. For auditory memory, if an animal hears a danger sound, it will need to remember (auditory primacy, short delay) the starting point of the sound to determine whether the sound (e.g., one made by a predator) is coming toward it or going away from it. If, on the other hand, an animal hears a danger sound that stops, it will need to remember (auditory recency, long delay) where the sound stopped, so as to avoid the spot where a potential predator might be hiding.

Explaining auditory SPFs requires a different approach from that of the dual-store (STM/LTM) models mentioned in the introduction. In dual-store models, evidence for the STM store is often decay of the (visual) recency (e.g., Atkinson \& Shiffrin, 1968; Gillund \& Shiffrin, 1984). The monkey's auditory recency effect cannot represent STM, because a recency effect is not present initially and its later appearance is more like LTM than STM.

The change from a pure primacy SPF to a pure recency SPF suggests dynamically changing processes and interference. PI refers to the negative effects of prior learning on retention of material learned later, and retroactive interference $(\mathrm{RI})$ refers to the negative effects of later learning on retention of material learned earlier (see Crowder, 1976, for a review). Learning experiments with paired associates have shown that RI is strong immediately after learning but weakens with time and that PI is weak immediately after learning but strengthens with time (e.g., Postman, Stark, \& Fraser, 1968). This pattern of interference has been hypothesized to account for visual SPFs (e.g., Wright, 1998a), although tests of interference were not conducted. An interference account of the auditory SPF would require interference processes opposite to those for visual memory. In auditory memory, PI initially should be strong but should dissipate with time, and RI initially should be weak but should strengthen with time. This hypothesis was tested and supported by the results of two auditory memory studies (Wright, 1999a; Wright \& Roediger, 2002). Among the findings, the first list items were shown to interfere (proactively) with memory of the last list items. By di- minishing or eliminating this interference, memory for the last items greatly improved, which ruled out lack of consolidation as an explanation for poor memory of the last list items. At long delays, the last list items were shown to interfere (retroactively) with the monkey's memory of the first list items. By diminishing or eliminating this interference, memory for the first items greatly improved, which ruled out forgetting (i.e., memory decay) as an explanation for poor memory of the first list items. These results, I think, provide the most compelling evidence to date that interference is instrumental in determining the shape of an SPF.

The theory, like a row of receding telephone poles with Alternative explanations of dynamically changing SPFs include temporal distinctiveness (e.g., Knoedler et al., 1999; Neath, 1993; Neath \& Knoedler, 1994) and storage versus retrieval strength (Bjork, 2001). An item's temporal distinctiveness changes with time, according to the theory, like a row of receding telephone poles with diminishing separation. Said otherwise, with time, all items become less temporally distinct. But as Bjork (2001) has pointed out, temporal distinctiveness cannot account for absolute (as opposed to relative) memory recovery, as shown by the visual primacy effect. To account for absolute recovery, Bjork proposed a storage-strength versus retrieval-strength model. But this model was based on repeated learning of some material and would not apply to absolute recovery following single presentations of lists (but see Bjork \& Bjork, 1992). The view presented in this article is that retrieval failure is the result of interference. Our experiments have shown that (proactive) interference in monkey auditory memory causes retrieval failure for the last items in the list (Wright, 1999a; Wright $\&$ Roediger, 2002). Release from this (proactive) interference caused an absolute increase in recency memory, and the resulting (retroactive) interference caused retrieval failure for the first items in the list. With regard to the auditory memory results presented in this article and elsewhere, no explanation fares as well as interference.

In conclusion, the results presented in this article show that mixed-and blocked-delay tests produce equivalent monkey auditory SPFs. From these similar results, it can be concluded that blocked-delay SPFs are produced from the same underlying memory processes (e.g., interference) as mixed-delay SPFs and are not artifacts produced by blocking of the retention intervals. Thus, the complex patterns of serial position effects and the changes reported here and elsewhere (Wright, 1998b, 1999a; Wright \& Roediger, 2002) combine to provide a promising target for theories of serial position memory.

\section{REFERENCES}

Atkinson, R. C., \& Shiffrin, R. M. (1968). Human memory: A proposed system and its control processes. In K. W. Spence \& J. T. Spence (Eds.), The psychology of learning and motivation (Vol. 2, pp. 89-105). New York: Academic Press.

BAdDeley, A D., \& Hitch, G. J. (1977). Recency reexamined. In S. Dornic (Ed.), Attention and performance VI (pp. 647-667). Hillsdale, NJ: Erlbaum. 
BJork, R. A. (2001). Recency and recovery in human memory. In H. L. Roediger III, J. S. Nairne, I. Neath, \& A. M. Surprenant (Eds.), The nature of remembering: Essays in honor of Robert G. Crowder (pp. 211232). Washington, DC: American Psychological Association Press.

BJork, R. A., \& Whitten, W. B. (1974). Recency-sensitive retrieval processes in long-term free recall. Cognitive Psychology, 6, 173-189.

Bolhuis, J. J., \& VAN KAMPEN, H. S. (1988). Serial position curves in spatial memory of rats: Primacy and recency effects. Quarterly Journal of Experimental Psychology, 40B, 135-149.

Buchanan, J. P., Gill, T. V., \& Braggio, J. T. (1981). Serial position and clustering effects in chimpanzee's "free recall." Memory \& Cognition, 9, 651-660.

CAmpbell, R., \& Dodd, B. (1980). Hearing by eye. Quarterly Journal of Experimental Psychology, 32, 85-99.

CAST Ro, C. A. (1995). Primacy and recency effects in rhesus monkeys (Macaca mulatta) using serial probe recognition task: I. Effects of diazepam. Psychopharmacology, 119, 421-427.

CAstro, C. A. (1997). Primacy and recency effects in rhesus monkeys (Macaca mulatta) using a serial probe recognition task: II. Effects of atropine sulfate. Behavioral Neuroscience, 111, 676-682.

Castro, C. A., \& Larsen, T. (1992). Primacy and recency effects in nonhuman primates. Journal of Experimental Psychology: Animal Behavior Processes, 18, 335-340.

Crowder, R. G. (1976). Principles of learning and memory. Hillsdale, NJ: Erlbaum.

Crowder, R. G. (1993). Short-term memory: Where do we stand? Memory \& Cognition, 21, 142-145.

Gillund, G., \& Shiffrin, R. M. (1984). A retrieval model for both recognition and recall. Psychological Review, 91, 1-67.

Glanzer, M., \& Cunitz, A. R. (1966). Two storage mechanisms in free recall. Journal of Verbal Learning \& Verbal Behavior, 5, 351-360.

Glenberg, A. M., Bradley, M. M., Kraus, T. A., \& Renzaglia, G. J. (1983). Studies of the long-term recency effect: Support for a contextually guided retrieval hypothesis. Journal of Experimental Psychology: Learning, Memory, \& Cognition, 9, 231-255.

GreENE, R. L. (1992). Human memory. Hillsdale, NJ: Erlbaum.

Harper, D. N., Mclean, A. P., \& Dalrymple-Alford, J. C. (1993). List item memory in rats: Effects of delay and delay task. Journal of Experimental Psychology: Animal Behavior Processes, 19, 307-316.

Harrison, J. M., Iversen, S. D., \& Pratt, S. R. (1977). Control of responding by location of auditory stimuli: Adjacency of sound and response. Journal of the Experimental Analysis of Behavior, 28, 243 251.

Kesner, R. P., \& NovaK, J. M. (1982). Serial position curve in rats: Role of the dorsal hippocampus. Science, 218, 173-175.

Knoedler, A. J., Hellwig, K. A., \& Neath, I. (1999). The shift from recency to primacy with increasing delay. Journal of Experimental Psychology: Learning, Memory, \& Cognition, 25, 474-487.

KorSnes, M. S. (1995). Retention intervals and serial list memory. Perceptual \& Motor Skills, 80, 723-731.

Korsnes, M. S., \& MAgnussen, S. (1996). Age comparisons of serial position effects in short-term memory. Acta Psychologica, 94, 133-143.

Korsnes, M. S., Magnussen, S., \& Reinvang, I. (1996). Serial position effects in visual short-term memory for words and abstract spatial patterns. Scandinavian Journal of Psychology, 37, 62-73.

Neath, I. (1993). Distinctiveness and serial position effects in recognition. Memory \& Cognition, 21, 689-698.

Neath, I., \& Knoedler, A. J. (1994). Distinctiveness and serial position effects in recognition and sentence processing. Journal of Memory \& Language, 33, 776-795.

Postman, L., \& Phillips, L. (1965). Short-term temporal changes in free-recall. Quarterly Journal of Experimental Psychology, 17, 132138.

Postman, L., Stark, K., \& Fraser, J. (1968). Temporal changes in interference. Journal of Verbal Learning \& Verbal Behavior, 7, 672694.

Reed, P., Croft, H., \& Yeomans, M. (1996). Rats' memory for serially presented novel flavours: Evidence for non-spatial primacy effects. Quarterly Journal of Experimental Psychology, 49B, 174-187.

Roberts, W. A., \& Kraemer, P. J. (1981). Recognition memory for lists of visual stimuli in monkeys and humans. Animal Learning \& Behavior, 9, 587-594.

Roediger, H. L., III, \& Crowder, R. G. (1976). A serial position effect in recall of United States presidents. Bulletin of the Psychonomic Society, 8, 275-278.

Rundus, D. (1971). Analysis of rehearsal processes in free recall. Journal of Experimental Psychology, 89, 63-77.

SANDS, S. F., \& Wright, A. A. (1980a). Primate memory: Retention of serial list items by a rhesus monkey. Science, 209, 938-940.

SANDS, S. F., \& WRIGHT, A. A. (1980b). Serial probe recognition performance by a rhesus monkey and a human with 10- and 20-item lists. Journal of Experimental Psychology: Animal Behavior Processes, 6, 386-396.

Santiago, H. C., \& Wright, A. A. (1984). Pigeon memory: Same/ different concept learning, serial probe recognition acquisition and probe delay effects in the serial position function. Journal of Experimental Psychology: Animal Behavior Processes, 10, 498-512.

Shapiro, K. L., Jacobs, W. J., \& LoLordo, V. M. (1980). Stimulusreinforcer interactions in Pavlovian conditioning of pigeons: Implications for selective associations. Animal Learning \& Behavior, 8, 586-594.

Surprenant, A. M. (2001). Distinctiveness and serial position effects in tonal sequences. Perception \& Psychophysics, 63, 737-745.

Wright, A. A. (1998a). Auditory and visual serial position functions obey different laws. Psychonomic Bulletin \& Review, 5, 564-584.

Wright, A. A. (1998b). Auditory list memory in rhesus monkeys. Psychological Science, 9, 91-98.

WRIGHT, A. A. (1999a). Auditory list memory and interference in monkeys. Journal of Experimental Psychology: Animal Behavior Processes, 25, 284-296.

Wright, A. A. (1999b). Visual list memory in capuchin monkeys (Cebus apella). Journal of Comparative Psychology, 113, 74-80.

Wright, A. A., Cook, R. G., Rivera, J. J., Shyan, M. R., Neiworth, J. J., \& JitsumoRI, M. (1990). Naming, rehearsal, and interstimulus interval effects in memory processing. Journal of Experimental Psychology: Learning, Memory, \& Cognition, 16, 1043-1059.

Wright, A. A., \& RiverA, J. J. (1997). Memory of auditory lists by rhesus monkeys (Macaca mulatta). Journal of Experimental Psychology: Animal Behavior Processes, 23, 1-9.

Wright, A. A., \& Roediger, H. L., III (2002). Interference processes in monkey auditory list memory. Manuscript submitted for publication.

Wright, A. A., Santiago, H. C., \& Sands, S. F. (1984). Monkey memory: Same/different concept learning, serial probe acquisition, and probe delay effects. Journal of Experimental Psychology: Animal Behavior Processes, 10, 513-529.

Wright, A. A., Santiago, H. C., Sands, S. F., Kendrick, D. F., \& Cook, R. G. (1985). Memory processing of serial lists by pigeons, monkeys, and people. Science, 229, 287-289.

(Manuscript received October 10, 2001; revision accepted for publication February 14, 2002.) 